\title{
Effect of Benzothiadiazole on Transmission of X-Disease Phytoplasma by the Vector Colladonus montanus to Arabidopsis thaliana, a New Experimental Host Plant
}

\author{
Alberto Bressan, Department of Environmental Science, Policy and Management, University of California, Berke- \\ ley 94720-3114, and Università di Padova, Dipartimento di Agronomia Ambientale e Produzioni Vegetali, Viale \\ dell'Università 16, 35020 Legnaro, Italy; and Alexander H. Purcell, Department of Environmental Science, Policy \\ and Management, University of California, Berkeley
}

\begin{abstract}
Bressan, A., and Purcell, A. H. 2005. Effect of benzothiadiazole on transmission of X-disease phytoplasma by the vector Colladonus montanus to Arabidopsis thaliana, a new experimental host plant. Plant Dis. 89:1121-1124.

Colladonus montanus (Van Duzee), a leafhopper vector of X-disease phytoplasma (Xp), efficiently transmitted the pathogen to Arabidopsis thaliana Columbia wild type. During transmission trials, the phytoplasma was inoculated into 22-, 34-, and 40-day-old plants. Phytoplasma infections were confirmed by polymerase chain reaction (PCR) using primers specific for Xp. Symptoms in Xp-positive A. thaliana were overall stunting and reduced or no fruit (silques). All symptom-free plants were PCR negative. Leafhopper nymphs free of Xp that fed on diseased $A$. thaliana acquired and transmitted $\mathrm{Xp}$ to celery plants, a diagnostic host, causing typical $\mathrm{X}$ disease symptoms. Foliar spray applications of the plant resistance elicitor benzothiadiazole (BTH) to A. thaliana 1 week before phytoplasma inoculation significantly reduced phytoplasma infection, ranging from an infection rate of $73.7 \%$ for untreated plants to 50 and $35 \%$ for plants treated with 1.2 and $4.8 \mathrm{mM} \mathrm{BTH}$, respectively. Vector leafhoppers survival was significantly reduced on BTH-treated $A$. thaliana compared with leafhoppers on nontreated plants, suggesting that systemic acquired resistance in this plant may have some detrimental effect on the leafhopper C. montanus.
\end{abstract}

Additional keywords: mollicute, SAR

Phytoplasmas are cell-wall-less members of the bacterial class Mollicutes that are obligate parasites of plants and insect vectors. Phytoplasmas cause hundreds of plant diseases, several of which have worldwide agricultural significance (17). The plant host range of some phytoplasma strains may be very wide. This is the case for X-disease phytoplasma (Xp). Although $\mathrm{X}$-disease is an economic disease of stone fruit trees such as cherry and peach $(10,18)$, the pathogen infects a wide range of herbaceous plants $(3,6,12,14)$ in both eastern and western North America.

Using the polyphagous leafhopper (Hemiptera: Cicadellidae) vector Colladonus montanus (Van Duzee) (20), Frazier and Jensen (6) and Jensen (12) experimen-

Corresponding author: A. H. Purcell

E-mail: Purcell@nature.berkeley.edu

This research was partially supported by the Fondazione Ing. Aldo Gini, University of Padova, Italy.

Accepted for publication 3 June 2005.

DOI: 10.1094/PD-89-1121

(C) 2005 The American Phytopathological Society tally transmitted the western strain of Xdisease causal agent (then incorrectly assumed to be a virus) from infected celery to 12 different plant species. Chiykowski and Sinha (3) reported 17 host species of an eastern strain of X-disease vectored by Paraphlepsius irroratus (Say). We have recorded disease symptoms from numerous other plant species inoculated with infectious leafhopper vectors (A. H. Purcell, unpublished).

The small and fast-growing crucifer Arabidopsis thaliana has become widely used in plant genetic studies, and its genome has been completely sequenced (2). Moreover, the small-sized and fastmaturing $A$. thaliana has numerous ecotypes that are available for researchers. $A$. thaliana may provide a useful tool to increase knowledge of molecular details of plant-phytoplasma interactions (5). To date, the beet leafhopper-transmitted virescence (BLTV) phytoplasma $(5,8)$ and Spiroplasma citri $(4,5)$ are recognized as mollicute pathogens of $A$. thaliana. Because phytoplasmas have never been cultured, molecular genetic methods have become indispensable tools for studies of phytoplasma biology and pathology.
Systemic acquired resistance (SAR) is an inducible resistance mechanism in plants that provides resistance against a broad spectrum of plant pathogens: viruses, fungi, and bacteria. This mechanism of resistance is activated in several plant species by natural attacks of pathogens. Alternatively, chemicals (elicitors) have been developed to apply directly to plant tissues $(13,15)$ to activate SAR. To our knowledge, no data are available on the effect of SAR on phytoplasma infections.

This report describes our use of the leafhopper vector $C$. montanus and $\mathrm{Xp}$ infected celery as a source of inoculum for the leafhopper, to test $A$. thaliana as an experimental host of Xp. Additionally using the elicitor benzo-(1,2,3)-thiadiazole-7carbothioic acid S-methyl ester (BTH), an inducer of SAR in A. thaliana (15), we assessed the effect of SAR in the Xp infection of A. thaliana inoculated by infective C. montanus.

\section{MATERIALS AND METHODS}

Leafhopper rearing and phytoplasma transmission. The leafhopper vector $C$. montanus was reared on healthy celery plants in a greenhouse insectary. Infectious insects were produced by confining groups (approximately 100 to 200) of mid-instar nymphs on celery with symptoms of Xdisease (strain GVX, originally transmitted to celery by $C$. montanus from sweet cherry, Prunus avium L., near Lodi, CA) for an acquisition access period of 15 days. Although we hereafter refer to these as "infectious" insects, it was likely that not all insects exposed to Xp-infected plants acquired $\mathrm{Xp}$ or became capable of transmitting it to plants even if internally infected by the phytoplasma. About 35 days later, we transferred the leafhoppers to 45to 60-day-old healthy celery seedlings to maintain phytoplasma on plants and to provide sources for later vector acquisition. The median latent period of $\mathrm{Xp}$ in $C$. montanus is 28 to 35 days, depending on temperature (7). For the transmission trials (see below) we used cylindrical cellulose acetate-butyrate plastic cages $(5 \mathrm{~cm}$ in diameter and $10 \mathrm{~cm}$ high) ventilated with Dacron organdie windows to singly con- 
fine insects on test plants for an inoculation access period of 2 days. At the end of each transmission assay, we removed leafhoppers from each plant and recorded insect survival.

Plants. Seeds of A. thaliana Columbia wild-type were sowed singly in sterile potting compost in 5-cm-wide pots and left in the dark for 4 days at $4^{\circ} \mathrm{C}$. Trays with pots then were maintained under fluorescent lights $(8 \mathrm{~h}$ of light and $16 \mathrm{~h}$ of darkness per day) at a temperature of $25 \pm 2^{\circ} \mathrm{C}$. For 20 days following inoculation with infectious leafhoppers, we maintained the plants in a heated greenhouse with natural light and temperature $\left(26 \pm 5^{\circ} \mathrm{C}\right)$ to complete the disease incubation period (time for symptoms to appear). Seeds of celery were germinated in a sand-peat soil in plastic pots, maintained in the greenhouse, and used when the plants were about 45 days old.

Transmission trials and phytoplasma symptoms in $\boldsymbol{A}$. thaliana. To test the pathogenicity of $\mathrm{Xp}$ to $A$. thaliana, we confined single infectious $C$. montanus on each of 16 A. thaliana seedlings for each of the three separate treatments, using 22-, 34-, and 40-day-old plants for an inoculation access period of 2 days. Alternatively, infective leafhoppers from the same acquisition cohort were confined singly on 16 celery seedlings to compare rates of $\mathrm{Xp}$ transmission between two host plant species. $C$. montanus that had never been exposed to $\mathrm{Xp}$ were maintained on nine $A$. thaliana plants for the same inoculation access period as controls to distinguish symptoms of leafhopper feeding damage from symptoms caused by phytoplasma infection. For transmission from symptomatic A. thaliana plants to celery seedlings, we used six suspected X-disease-

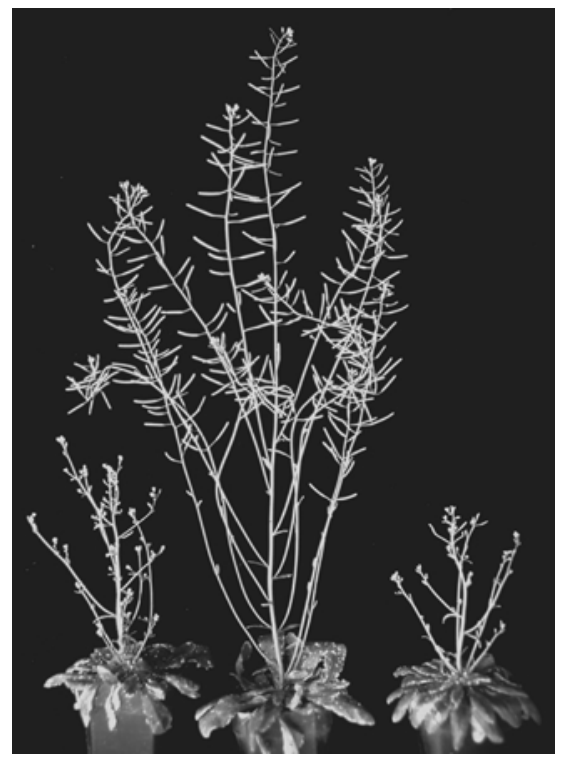

Fig. 1. Arabidopsis thaliana plants affected by $\mathrm{X}$-disease phytoplasma on each side of the uninfected plant in center. Note stunting and lack of silques production in infected plants. symptomatic $A$. thaliana as phytoplasma sources to feed $60 \mathrm{C}$. montanus nymphs for an acquisition access period of 7 days, followed by weekly transfer to celery. From this group, we tested 18 leafhoppers singly for 7 days of inoculation access on celery. Plants with the same treatments were spatially randomized during transmission and during the incubation period. After inoculation, every 2 days, plants were checked carefully for possible symptoms associated to phytoplasma infection. Plants with possible symptoms were compared with plant controls that had been inoculated with noninfectious $C$. montanus. We looked for leaf chlorosis and root necrosis in celery and leaf discoloration, deformation, stunting of the stems, and tissue necrosis for A. thaliana.

Effect of BTH on phytoplasma transmission. BTH was supplied by Syngenta Corporation as $50 \%$ active ingredient in a wettable powder formulation. It was diluted with sterile water and applied to upper leaf surfaces to run-off by using a spray bottle. Elicitor application was made 7 days before phytoplasma inoculation using infectious leafhoppers. We used 80 30-day-old $A$. thaliana seedlings in the transmission trial in four different treatments: 20 plants each were sprayed with a solution of 1.2 or $4.8 \mathrm{mM} \mathrm{BTH}$, or with sterile water. These 60 plants were inoculated with infectious $C$. montanus; a fourth treatment of 20 plants was mock inoculated with noninfectious insects. We recorded $C$. montanus survival at the end of the transmission test. To avoid oviposition, we used only male leafhoppers to inoculate A. thaliana. After treatments, plants that were caged with infectious or noninfectious insects were maintained in a randomized spatial design as during the previous trial. Additionally, when plants were placed in the long-day greenhouse, their position was changed periodically to eliminate any gradient in light or temperature that could affect expression of symptoms. Inoculated plants were observed carefully every 2 days for possible phytoplasma symptoms for 8 weeks. As a reference, we used phytoplasma symptoms in A. thaliana that were identified during the former experiment.

Polymerase chain reaction. We periodically assayed celery and A. thaliana for phytoplasma infection by a polymerase chain reaction (PCR) procedure (19). Approximately $0.3 \mathrm{~g}$ of leaf main veins was used for DNA extraction. When $A$. thaliana plants were used for DNA extraction, part of the shoots was sampled in addition to the leaf veins. We extracted DNA from each sample according to a protocol (1) as modified by B. C. Kirkpatrick (University of California, Davis).

DNA from experimentally infected Xdiseased celery and healthy celery plants were used as positive and healthy controls, respectively, in all amplifications. A direct
PCR procedure was used with the primer pairs fP1 and rWXint (19). For specific detection of $\mathrm{Xp}$, these primer pairs amplify a region of approximately $1,600 \mathrm{bp}$ in the 16Sr DNA and the adjacent spacer region of Xp (19). For PCR, each reaction contained 1× PCR buffer (Perkin-Elmer, Wellsley, MA), $50 \mathrm{ng}$ of template DNA, $0.5 \mu \mathrm{M}$ each primer, $150 \mu \mathrm{M}$ each dNTP, and $1 \mathrm{U}$ of AmpliTaq DNA polymerase (PerkinElmer) in a final volume of $30 \mu \mathrm{l}$. Amplification consisted of 30 cycles of denaturation for $1 \mathrm{~min}$ at $94^{\circ} \mathrm{C}$ and annealing for 1 min at $48^{\circ} \mathrm{C}$, followed by final extension for $2 \mathrm{~min}$ at $72^{\circ} \mathrm{C}$. PCR products were separated by electrophoresis in $1 \%$ agarose gel stained with ethidium bromide and observed under UV illumination.

Statistics. Differences among treatments were tested for significance using $\chi^{2}$ with Yates correction for continuity, and level of significance $(P)$ was fixed at 0.05 using Statistica (ver. 6.1; StatSoft Italy, Padova, Italy).

\section{RESULTS}

Symptoms of $\mathrm{Xp}$ in A. thaliana. Beginning 35 to 45 days after vector inoculation during the reproductive phase (induced by long days), numerous $A$. thaliana plants had pronounced stunting, shortened internodes, aborted flowers, and fewer and smaller silques (Fig. 1) without seeds. The smallest leaves of the central stems of such plants became yellow, then necrotic. PCR assays yielded the expected size amplicon for Xp in 29 symptomatic plants. No amplicons were produced from sampled tissues from four healthy control plants inoculated with noninfectious leafhoppers. Infected plants died within 6 to 7 weeks after inoculation.

Transmission of $\mathrm{Xp}$ to and from $A$. thaliana. The leafhopper $C$. montanus did not cause noticeable feeding damage on $A$. thaliana plants during the transmission process. In our preliminary experiments, leafhopper females laid eggs on $A$. thaliana, and nymphs' feeding caused small chlorotic spots and slight leaf deformation. For this reason, we used only adult males for phytoplasma transmission. C. montanus transmitted Xp to 26 of 48 A. thaliana and 6 of 16 celery seedlings (Table 1). Very young plants of $A$. thaliana were readily infected with $\mathrm{Xp}$ using leafhopper transmission, despite low vector survival (Table 1). There was no evidence that plant age or plant species (Arabidopsis sp. versus celery) affected transmission rate or vector survival $\left(\chi^{2} ; P \geq 0.05\right)$. In the acquisition test from diseased $A$. thaliana, 4 of 18 leafhopper nymphs acquired phytoplasma and transmitted the pathogen to celery, which developed typical X-disease symptoms.

Effect of BTH on the transmission of Xp to and leafhopper survival on $A$. thaliana. BTH applications apparently reduced the size and modified the growth 
of A. thaliana leaves. A lower fraction of BTH dosages (1.2 and $4.8 \mathrm{mM}$ ) became infected with Xp compared with untreated plants: 16 diseased plants of 38 inoculated BTH-treated plants (42\%) versus 14 diseased plants of 19 untreated plants $(73.7 \%)$ $\left(\chi^{2}=3.88\right.$, df $=1, P=0.049$; Table 2). With the concentration of $1.2 \mathrm{mM} \mathrm{BTH}$, the fraction of inoculated plants that became diseased was slightly less but not statistically significant compared with untreated plants (50 and $74 \%$, respectively) $\left(\chi^{2}=1.31, \mathrm{df}=1, P=0.252\right)$. The higher dose of BTH reduced the incidence of phytoplasma infection to $35 \%$ when compared with unelicited plants with $74 \%$ infection $\left(\chi^{2}=4.41\right.$, df $=1, P=0.0357$; Table 2). Symptomatic activated $A$. amplification was obtained when symptomless A. thaliana were assayed by PCR.

C. montanus free of Xp survived longer than Xp-infected leafhoppers (Table 2): 16 of $20(80 \%)$ versus 18 of $57(31.6 \%)$ for all BTH treatments combined $\left(\chi^{2}=12.18\right.$, df $=1, P=0.0005)$. However, the survival on untreated Arabidopsis of $\mathrm{Xp}$-free insects was significantly different from $\mathrm{Xp}$ infected leafhoppers with no exposure to BTH $\left(\chi^{2}=4.0\right.$, df $\left.=1, P<0.04\right)$. The lower percentage of Xp-infected leafhoppers that survived on BTH-treated $A$. Xp-inoculated plants treated with both thaliana were PCR positive for $\mathrm{Xp}$; no

thaliana (24\% of 38 insects) was not significantly different from the percentage of Xp-infected leafhoppers that survived on untreated plants $\left(47 \%\right.$ of 19 insects; $\chi^{2}=$ $2.28, \mathrm{df}=1, P=0.13)$. A concentration of $1.2 \mathrm{mM}$ BTH had a negligible effect on the insects' survival $\left(\chi^{2}=0.27\right.$, df $=1, P=$ $0.6028)$, but the higher dose of BTH caused greater mortality $\left(\chi^{2}=6.72, \mathrm{df}=1\right.$, $P=0.0095$; Table 2).

\section{DISCUSSION}

Our results demonstrated that $A$. thaliana is a host of Xp. Distinctive symptoms were closely correlated with infection confirmed by PCR assays and by leafhopper acquisition of the pathogen from infected A. thaliana. The method we used to produce diseased plants was as efficient as for other phytoplasmas using short inoculation periods and few leafhopper vectors per plant. A limiting problem for the use of A. thaliana is the lengthy $35-$ to 45 -day incubation period, relative to the short life cycle of $A$. thaliana.

Recently, Lherminier et al. (16) observed morphological and cytological modifications in the phloem tissues of phytoplasma-infected tobacco activated with both cryptogein and oligandrin elicitines, which prevent the symptoms of stolbur phytoplasma infection. $\mathrm{P}$ protein plugs and occlusion of pore sites by cal-

Table 1. Transmission of X-disease phytoplasma by Colladonus montanus leafhoppers to Arabidopsis thaliana or celery seedlings ${ }^{\mathrm{X}}$

\begin{tabular}{|c|c|c|c|c|}
\hline \multirow[b]{2}{*}{ Plant species, age (days) } & \multicolumn{2}{|c|}{ Infected plants $^{\mathrm{y}}$} & \multicolumn{2}{|c|}{ Leafhopper survival } \\
\hline & Ratio & Percent & Ratio & Percent \\
\hline \multicolumn{5}{|l|}{ A. thaliana } \\
\hline 22 & $9 / 16$ & 56 & $3 / 16$ & 19 \\
\hline 34 & $10 / 16$ & 62.5 & $7 / 16$ & 44 \\
\hline 40 & $7 / 16$ & 44 & $11 / 16$ & 69 \\
\hline $22,34,40^{z}$ & $0 / 9$ & 0 & $6 / 9$ & 67 \\
\hline \multicolumn{5}{|l|}{ Celery } \\
\hline 45 & $6 / 16$ & 37.5 & $9 / 16$ & 56 \\
\hline
\end{tabular}

${ }^{\mathrm{x}}$ Leafhoppers acquired phytoplasma by feeding on infected celery for 15 days, followed by 20 days on healthy celery, then were confined singly on test plants. Survival is for the 2-day inoculation period on test plants.

${ }^{\text {y }}$ Symptoms on plants and polymerase chain reaction assays used to confirm phytoplasma infection are described in the text.

${ }^{\mathrm{z}}$ Controls: 9 A. thaliana were chosen (three plants per age) inoculated with noninfectious C. montanus.

Table 2. Effects of benzothiadiazole (BTH) treatments on leafhopper vector transmission of X-phytoplasma to and vector survival on Arabidopsis thaliana ${ }^{\mathrm{y}}$

\begin{tabular}{lccccc}
\hline & \multicolumn{2}{c}{ Infected plants $^{\mathbf{z}}$} & & \multicolumn{2}{c}{ Leafhopper survival } \\
\cline { 2 - 3 } \cline { 5 - 6 } BTH $(\mathbf{m M})$ & Ratio & Percent & & Ratio & Percent \\
\hline 0 & $14 / 19 \mathrm{a}$ & 74 & & $9 / 19 \mathrm{a}$ & 47 \\
1.2 & $9 / 18 \mathrm{ab}$ & 50 & & $7 / 18 \mathrm{a}$ & 39 \\
4.8 & $7 / 20 \mathrm{~b}$ & 35 & & $2 / 20 \mathrm{~b}$ & 10 \\
Uninoculated & $0 / 20 \mathrm{c}$ & 0 & & $16 / 20 \mathrm{c}$ & 80 \\
\hline
\end{tabular}

${ }^{\mathrm{y}}$ BTH or sterile water was sprayed on 30-day-old A. thaliana leaves 1 week before vector transmission. Leafhoppers acquired phytoplasma by feeding on infected celery for 15 days, followed by 20 days on healthy celery, then were confined singly on test plants. Survival is for the 2-day inoculation period on test plants. Fractions in the same column followed by the same letter are not significantly different ( $\chi^{2}$ comparisons, $P \leq 0.05$ )

${ }^{\mathrm{z}}$ Symptoms on plants and polymerase chain reaction assays used to confirm phytoplasma infection are described in the text. lose occurred in sieve elements of treated tobacco plants, and these modifications might have prevented the movement of phloem-restricted pathogens (16). The reduced transmission of $\mathrm{Xp}$ in BTHtreated A. thaliana may have been caused by plants' acquired resistance to phytoplasma colonization and its movement in the phloem tissues, but it also is possible that BTH elicited plant responses that inhibited vector feeding and, hence, transmission. The reduced survival of $C$. montanus on BTH-treated A. thaliana is consistent with this second possibility.

In our experiment, at least two factors might have influenced the mortality of $C$. montanus. First, Xp might have induced a premature mortality in the leafhoppers, as previously reported (11). The survival of Xp-infected insects was lower than noninfected ones on nonactivated A. thaliana (although the difference was not significant). Secondly, SAR induced in $A$. thaliana by BTH applications may have reduced leafhopper survival on the treated plants, as suggested by the lower survival rates of Xp-infected insects on $4.8 \mathrm{mM}$ BTH-activated plants than on nonactivated plants. Some evidence indicates that SAR has a slight or negligible effect on phytophagous insects such as some cotton pests (9), but this does not appear to be the case for the leafhopper C. montanus.

The increasing store of genetic data resulting from the adoption of A. thaliana as a model system has accelerated our understanding of plant development and physiological processes at the molecular level. The susceptibility of $A$. thaliana to Xdisease and inducible SAR to $\mathrm{Xp}$ in $A$. thaliana should facilitate molecular and genetic investigations of plant reactions and SAR to phytoplasmas.

\section{ACKNOWLEDGMENTS}

We thank B. Staskowicz for providing Arabidopsis $\mathrm{Col} 0$ seed; E. Norberg and T. Wistrom for the helpful advice on greenhouse procedures; $\mathrm{L}$. Liefting and B. Kirkpatrick for helpful support on extraction and PCR procedures; and R. Almeida, T. Wistrom, and C. M. Curley for reviewing the manuscript.

\section{LITERATURE CITED}

1. Ahrens, U., and Seemuller, E. 1992. Detection of DNA of plant pathogenic mycoplasma like organisms by a polymerase chain reaction that amplifies a sequence of the 16S rRNA gene. Phytopathology 82:828-832.

2. Arabidopsis Genome Initiative (145 authors). 2000. Analysis of the genome sequence of the flowering plant Arabidopsis thaliana. Nature 408:796-815.

3. Chiykowski, L. N., and Sinha, R. C. 1982. Herbaceous host plant of peach eastern Xdisease agent. Can. J. Plant Pathol. 4:8-15.

4. Fletcher, J., and Eastman, C. E. 1991. Arabidopsis thaliana as an experimental host plant of Spiroplasma citri. (Abstr.) Phytopathology 81:1209.

5. Fletcher, J., Golino, D. A., and Eastman, C. E. 1993. Arabidopsis as an experimental host plant of the phytopathogenic mollicutes. Pages 99-108 in: Arabidopsis thaliana as a Model for Plant-Pathogen Interactions. K.R. Davis and R. 
Hammerschmidt, eds. American Phytopathological Society Press, St. Paul, MN.

6. Frazier, N. W., and Jensen, D. D. 1970. Strawberry, an experimental host of peach western X-disease. Phytopathology 60:1527-1528.

7. Gold, R. E., and Sylvester, E. S. 1982. Pathogen strains and leafhopper species as factors in the transmission of Western X-disease agent under varying light and temperature conditions. Hilgardia 3:1-43.

8. Golino, D. A., Shaw, M., and Rappaport, L. 1988. Infection of Arabidopsis thaliana (L.) with a mycoplasma like organism, the beet leafhopper transmitted virescence agent. Arabidopsis Inf. Svc. 26:9-14.

9. Inbar, M., Doostdar, H., Gerling D., and Mayer, T. R. 2001. Induction of systemic acquired resistance in cotton by BTH has a negligible effect on phytophagous insects. Entomol. Exp. Appl. 99:65-70.

10. Jensen, D. D. 1956. Insect transmission of virus between tree and herbaceous plants. Virology 2:249-260.
11. Jensen, D. D. 1959. A plant virus lethal to its insect vector. Virology 8:249-260.

12. Jensen, D. D. 1971. Herbaceous host plants of western X-disease agent. Phytopathology 61:1465-1470.

13. Kessmann, H., Staub, T., Hofmann, C., Maetzke, T., Herzog, J., Ward, E., Uknes, S., and Ryals, J. 1994. Induction of systemic acquired disease resistance in plants by chemicals. Annu. Rev. Phytopathol. 32:439-459.

14. Kunkel, L. O. 1944. Transmission of virus from X-diseased peach trees to herbaceous plants. (Abstr.) Phytopathology 34:1006.

15. Lawton, K. A., Friedrich, L., Hunt, M., Weymann, K., Delaney, T., Kessmann, H., Staub, T., and Ryals, J. 1996. Benzothiadiazole induces resistance in Arabidopsis by activation of the systemic acquired resistance signal transduction pathway. Plant $\mathrm{J}$. 10(1):71-82.

16. Lherminier, J., Benhamou, N., Larrue, J., Milat, M. L., Boudon-Padieu, E., Nicole, M., and Blein, J. P. 2003. Cytological characteriza- tion of elicitin-induced in tobacco plants infected by Phytophthora parasitica or phytoplasma. Phytopathology 93:1308-1319.

17. McCoy, R. E. Caudwell, A., Chang, C. J., and 16 other authors. 1989. Plant disease associated with mycoplasma-like organisms. Pages 545-640 in: The Mycoplasmas. R. F. Whitcomb and J. G. Tully, eds. Academic Press, New York.

18. Rawlins, T. E., and Thomas, H. E. 1941. The buckskin disease of cherry and other stone fruits. Phytopathology 31:916-925.

19. Smart, C. D., Schneider, B., Blomsquit, C. L., Guerra, L. J., Harrison, N. A., Ahrens, U., Lorenz, K. H., Seemüller, E., and Kirkpatrick, B. C. 1996. Phytoplasma-specific PCR primers based on sequences of 16S-23S rRNA spacer region. Appl. Environ. Microbiol. 62:2988 2993

20. Wolfe, H. R. 1955. Transmission of the western X-disease virus by the leafhopper, Colladonus montanus (Van Duzee). Plant Dis. Rep. 39:298-299. 